Supplement of Biogeosciences, 16, 4497-4516, 2019

https://doi.org/10.5194/bg-16-4497-2019-supplement

(C) Author(s) 2019. This work is distributed under

the Creative Commons Attribution 4.0 License.

(c) (1)

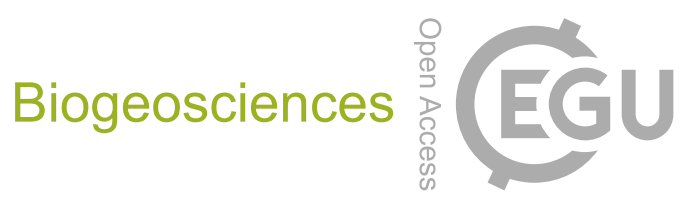

Supplement of

\title{
High-frequency measurements explain quantity and quality of dissolved organic carbon mobilization in a headwater catchment
}

Benedikt J. Werner et al.

Correspondence to: Benedikt J. Werner (benedikt.werner@ufz.de)

The copyright of individual parts of the supplement might differ from the CC BY 4.0 License. 


\section{S1 Description of fouling correction, onsite probe maintenance and water sampling}

After every 12 measurements $(3 \mathrm{~h})$, the probe was automatically cleaned with compressed air to inhibit bio-fouling and the accumulation of sediments.

Onsite maintenance was conducted biweekly (cleaning manually with detergent and $\mathrm{HCl}$, flushing with deionized water).

5 The first measurement after each cleaning was considered to represent the true absorption spectrum, with no bio-fouling or sediment influence. The difference between the last measurement before and the first one after maintenance showed how much the probe drifted within the two weeks since the last maintenance. Ahead of further (statistical) processing, each of the UV-Vis absorption spectra was corrected for this drift by subtracting an exponential function fitted to the raw data.

For $\mathrm{C}_{\mathrm{DOC}}$ measurements, sample water was filtered $(0.45 \mu \mathrm{m}$ cellulose acetate filter, Th.Geyer, Germany), acidified with

$1030 \% \mathrm{HCl}$ to $\mathrm{pH} 2$ and stored dark and cool in glass bottles until laboratory analysis was conducted.

\section{S2 Impact of hysteresis loop size on regression slopes}

Although hysteresis of C-Q relationship potentially could explain some deviations of our hydrological event models we did not take hysteresis into account. However the high overall $\mathrm{R}^{2}$ values of our event models (Figure 3 ) indicate that the influence of hysteresis on the $\mathrm{R}^{2}$ should be minor. Evaluating hysteresis index (HI) after Lloyd et al. (2016) Lloyd et al.

15 (2016) against $\mathrm{R}^{2}$ of events (Fig. S1) indicated a negative, but non-significant effect of magnitude of hysteresis (depicted as absolute value of $\mathrm{HI}$ ) on $\mathrm{R}^{2}$ (method of linear regression: $C_{D O C} \sim Q,\left[C_{D O C} \sim \log (Q)\right.$ was used where appropriate $]$ ). Overall, Pearson correlation of HI $\mathrm{R}^{2}$ of Events was $\mathrm{r}^{2}=0.12$ ( $\mathrm{r}_{\text {Pearson }}=-0.34, \mathrm{p}=0.07$ ), supporting the application of our method without explicit consideration of hysteresis effects.

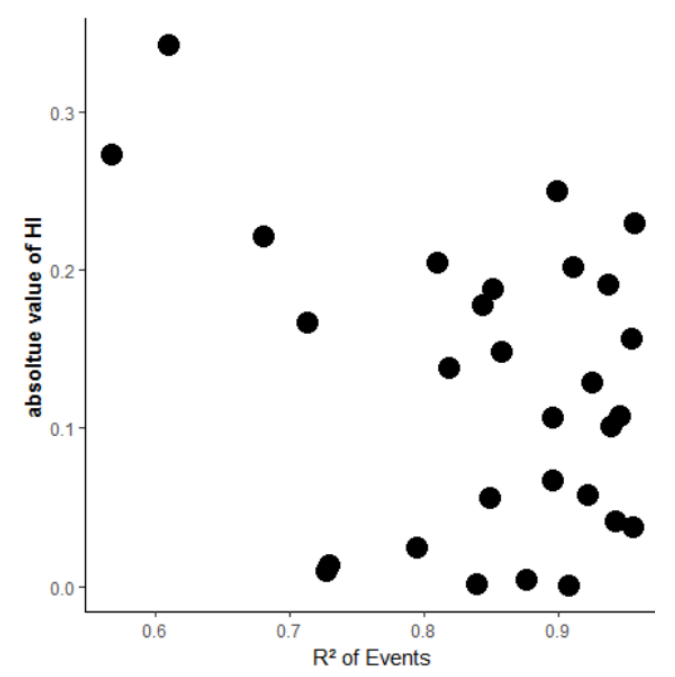

20 Fig. S1: Absolute value of the hysteresis index (HI) plotted against $\mathbf{R}^{2}$ of Events. 

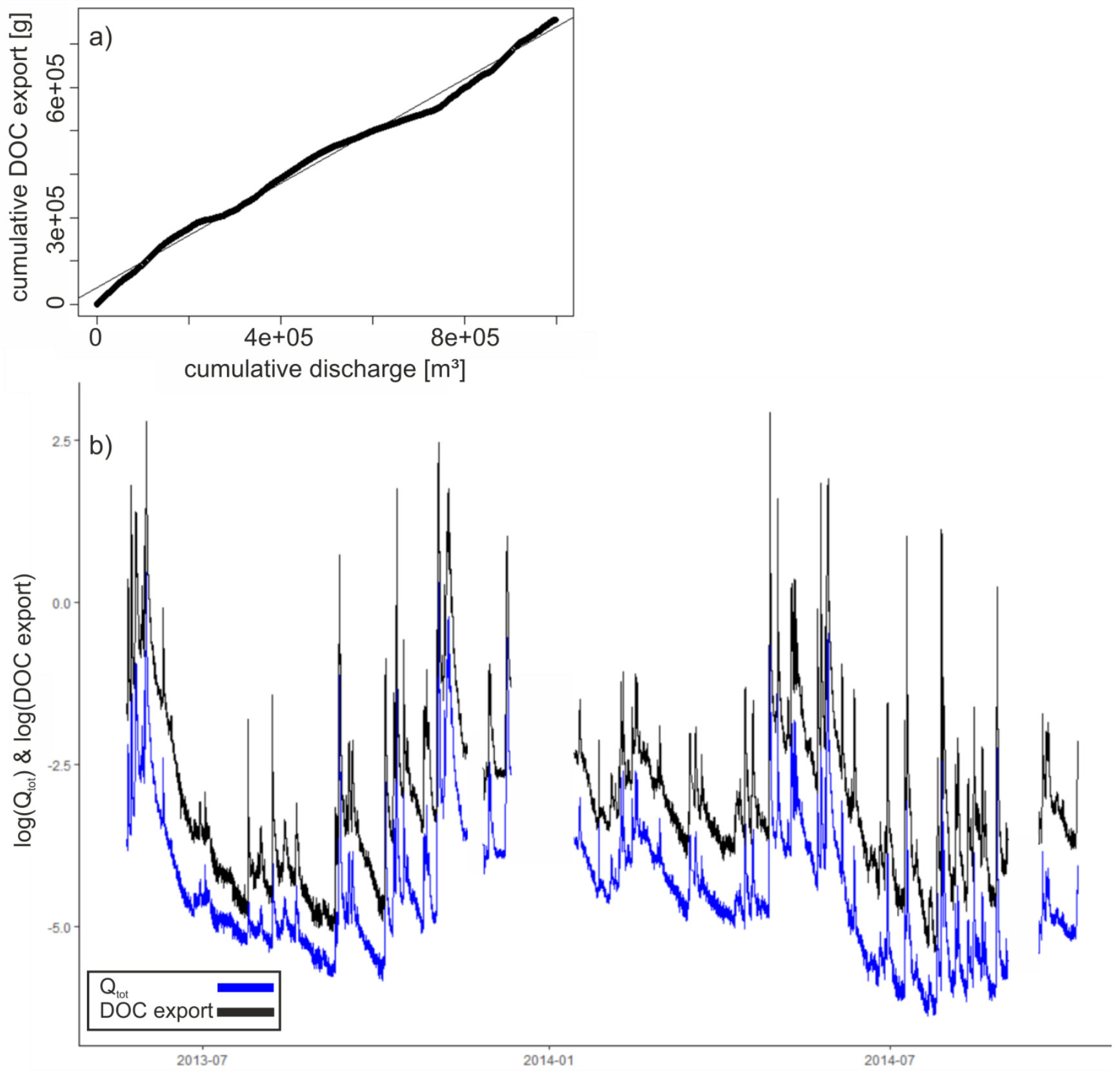

Fig. S2: a) cumulative discharge vs cumulative DOC export. Straight line indicates 1:1 line. b) Comparison of discharge and DOC export in log space over time. 

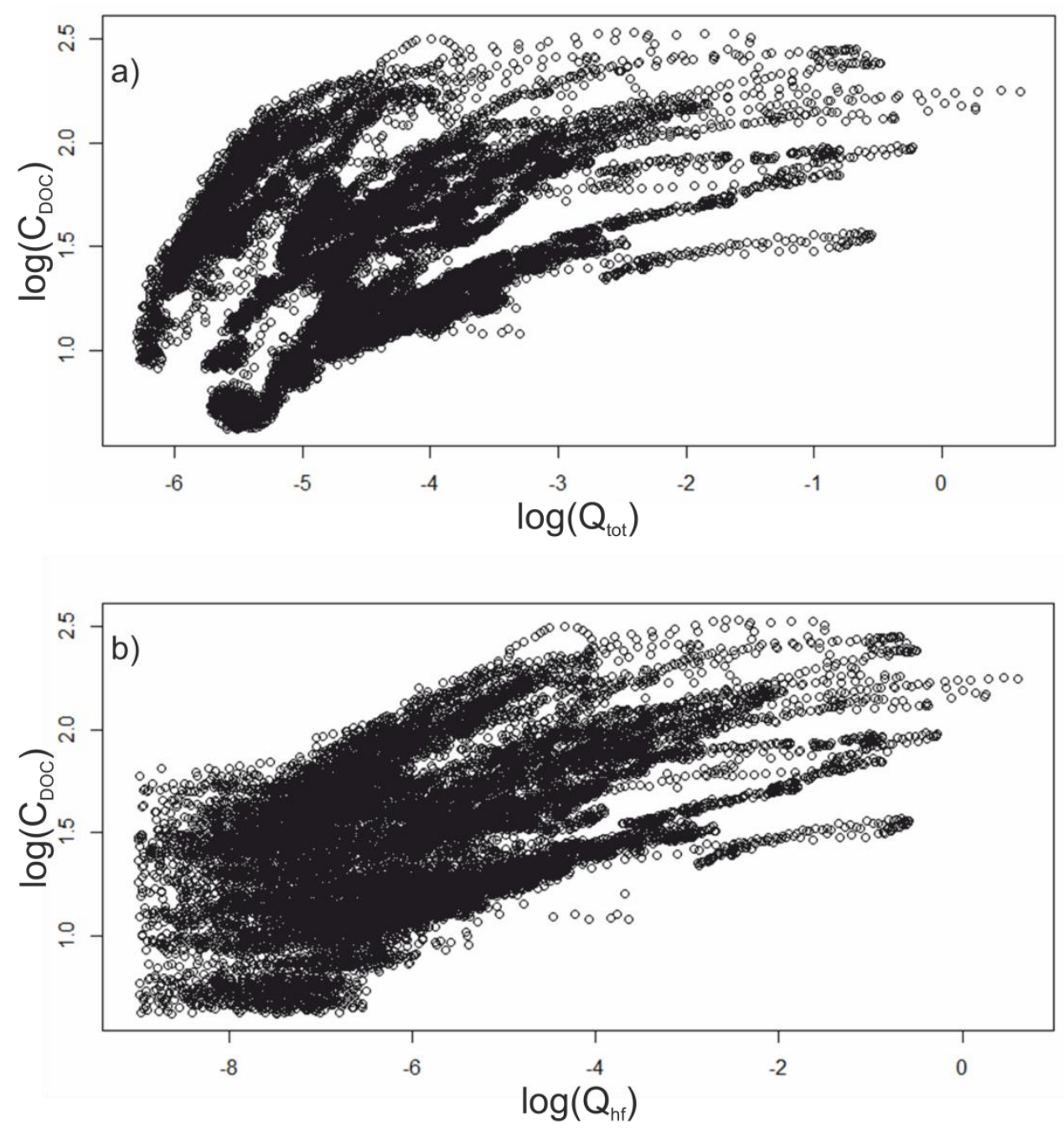

Fig. S3: Linearization of $C_{D O C}$ by (a) $Q_{t o t}$ and (b) $Q_{h f}$ in double log space. 

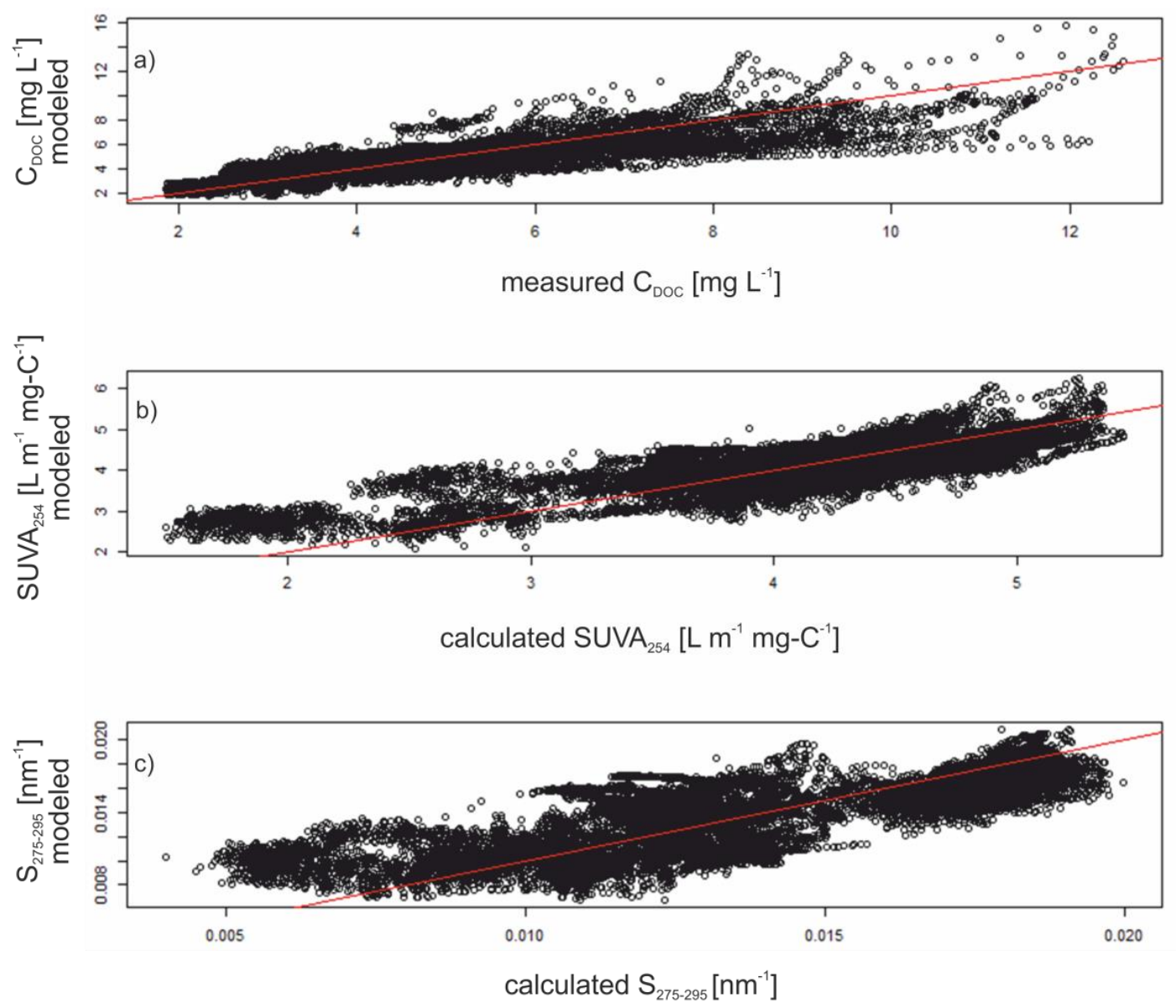

Fig. S4: Modelled vs. measured values of (a) $C_{D O C}$, (b) $S U V A_{254}$ and (c) $S_{275-295}$. Red line indicates 1:1 line. Maximum residuals are $6.03 \mathrm{mg} \mathrm{L}^{-1},-1.52 \mathrm{~L} \mathrm{~m}^{-1} \mathrm{mg-C} \mathrm{C}^{-1}$ and $-6.5 \times 10^{-3} \mathrm{~nm}^{-1}$ for the $C_{D O C}, S U V A_{254}$ and $S_{275-295}$ models, respectively. 

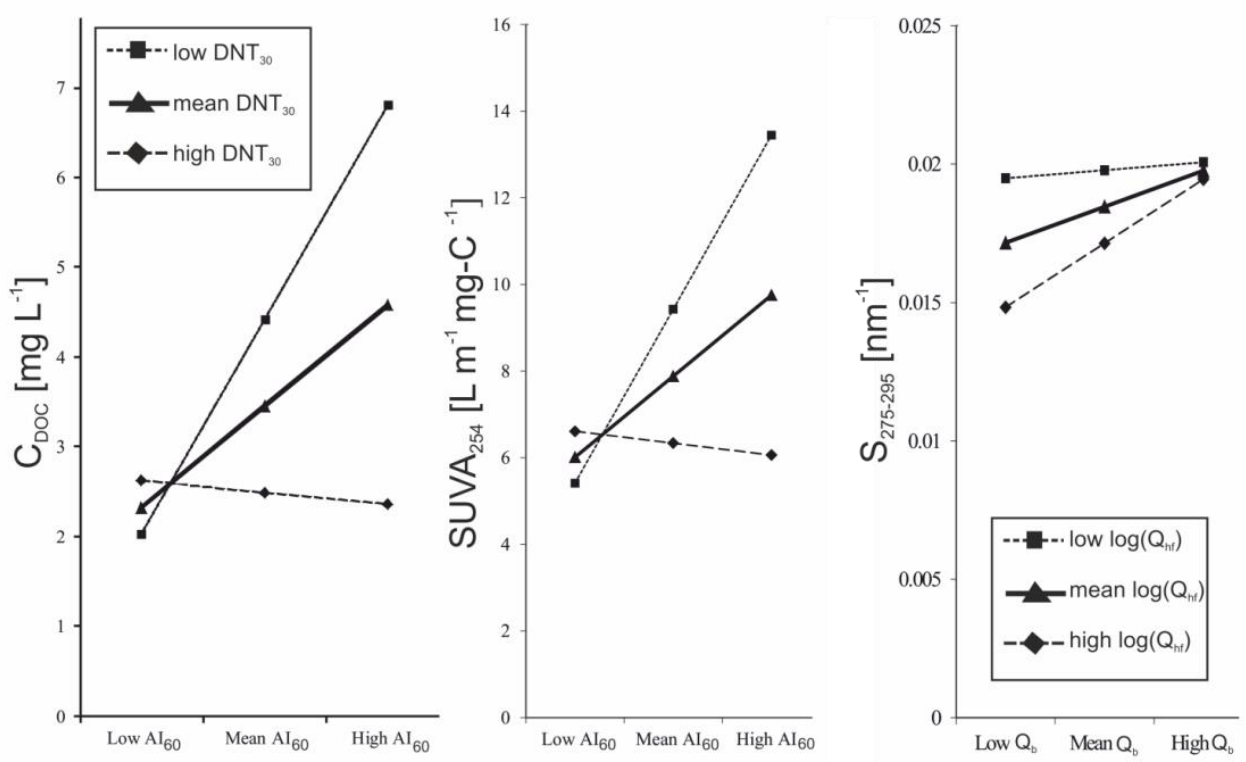

Fig. S5: Impact of the interaction $D N T_{30} \times A I_{60}$ on (a) $C_{D O C}$ and (b) $S U V A_{254}$. Panel (c) shows the impact of the interaction $D N T_{30} \times Q_{b}$ on $S_{275-295}$.

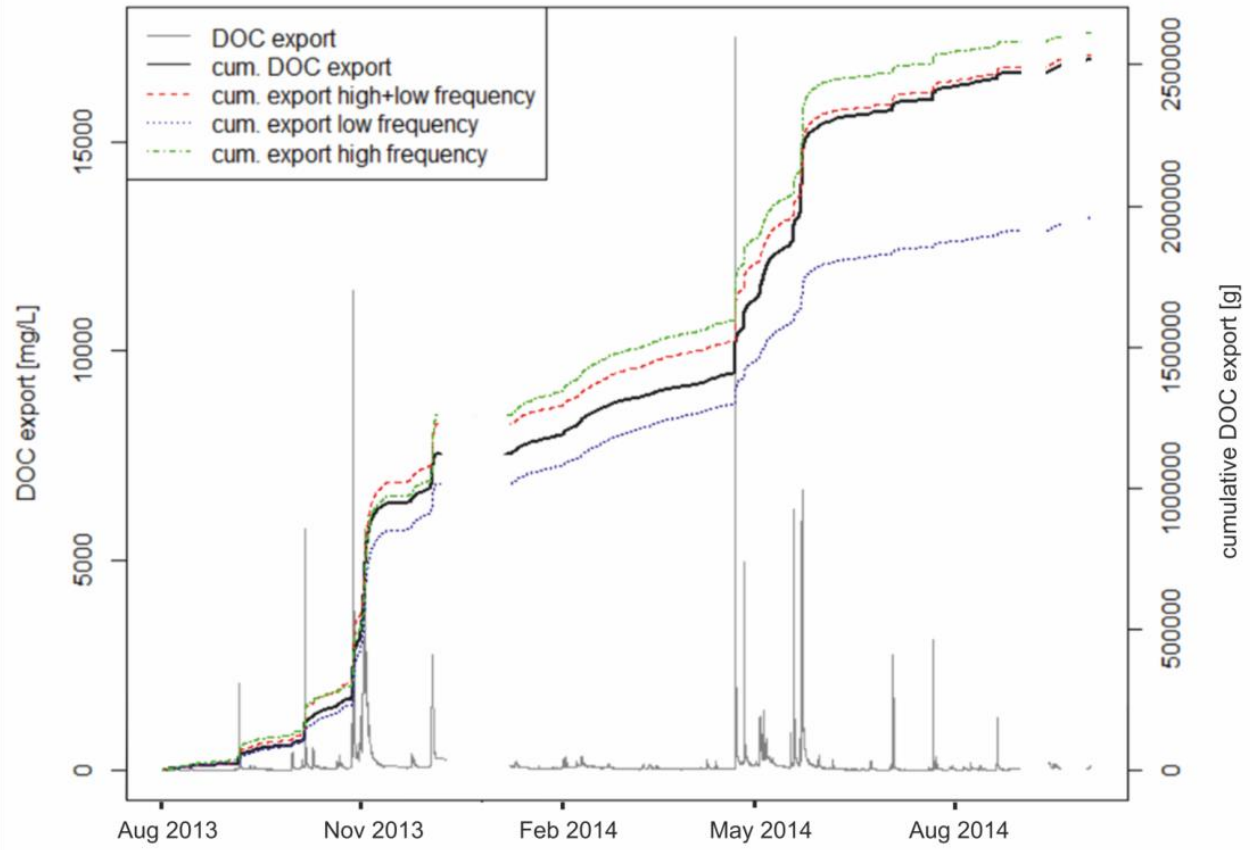

Fig. S 6: Cumulative modelled DOC export of high frequency $\left(Q_{h f}+Q_{b}+Q_{h f} \times Q_{b}\right)$, low frequency $\left(D_{N T_{30}}+A I_{60}+D N T_{30} \times A I_{60}\right)$ and their combination (Eq. (3)), calculated cumulative DOC export (black) and DOC concentration (grey). Nash-Sutcliffe efficiency of DOC export was 0.998, 0.979 and 0.783 . 


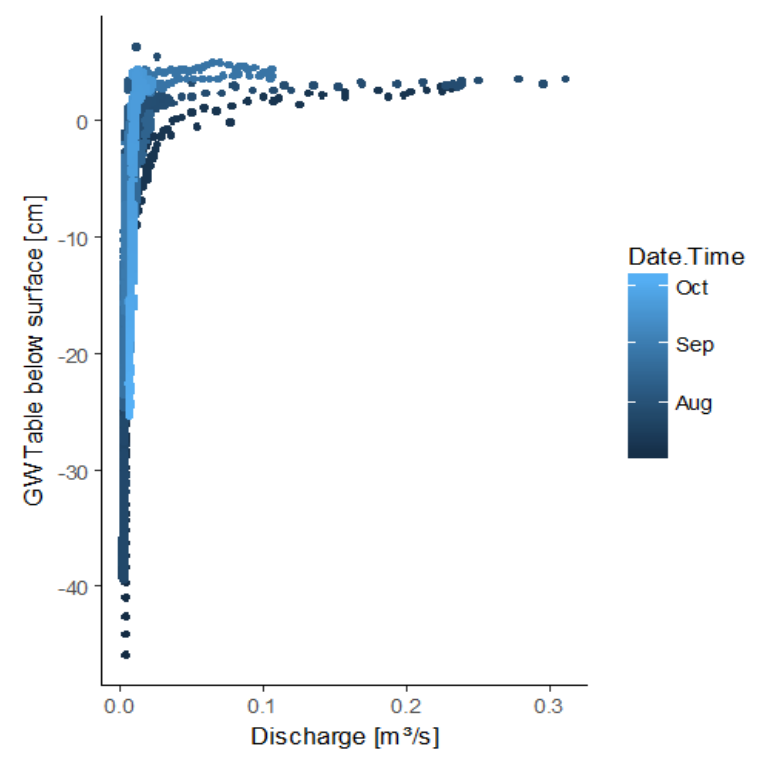

Fig. S 7: Relationship between stream discharge of the Rappbode stream and groundwater table of a nearby (30m) groundwater well. Colour coding indicates different time of the year.

Table S 1: Model evaluation of the $C_{D o C}, S U V A_{254}$ and $S_{275-295}$ models. All model parameters were highly significant (p<0.001).

\begin{tabular}{|c|c|c|c|c|c|c|c|c|c|}
\hline & \multicolumn{3}{|c|}{$C_{D O C}$ model } & \multicolumn{3}{|c|}{$S U V A_{254}$ model } & \multicolumn{3}{|c|}{$S_{275-295}$ model } \\
\hline & Estimate & Std. Error & $\mathrm{t}$ value & Estimate & Std. Error & $\mathrm{t}$ value & Estimate & Std. Error & $\mathrm{t}$ value \\
\hline Intercept & $2.6 \mathrm{E}+00$ & $1.1 \mathrm{E}-02$ & 234.5 & $6.6 \mathrm{E}+00$ & $2.5 \mathrm{E}-02$ & 261.6 & $2.7 \mathrm{E}-02$ & $1.3 \mathrm{E}-04$ & 212.9 \\
\hline$A I_{60}$ & $-5.2 \mathrm{E}-02$ & $1.0 \mathrm{E}-03$ & -52.0 & $-1.1 \mathrm{E}-01$ & $2.3 \mathrm{E}-03$ & -48.8 & $-5.1 \mathrm{E}-04$ & $1.1 \mathrm{E}-05$ & -45.2 \\
\hline$D N T_{30}$ & $-3.1 \mathrm{E}-04$ & $4.5 \mathrm{E}-06$ & -68.9 & $-6.3 \mathrm{E}-04$ & $1.0 \mathrm{E}-05$ & -62.2 & $-6.8 \mathrm{E}-07$ & $5.0 \mathrm{E}-08$ & -13.6 \\
\hline$Q_{b}$ & $-2.3 \mathrm{E}+01$ & $6.8 \mathrm{E}-01$ & -34.4 & $-6.8 \mathrm{E}+01$ & $1.5 \mathrm{E}+00$ & -44.1 & $-3.9 \mathrm{E}-01$ & 7.7E-03 & -50.8 \\
\hline$D N T_{30} \times Q_{b}$ & $-2.7 E-02$ & $8.1 \mathrm{E}-04$ & -33.8 & $-8.0 \mathrm{E}-02$ & $1.8 \mathrm{E}-03$ & -43.8 & $-3.8 \mathrm{E}-04$ & $9.2 \mathrm{E}-06$ & -41.9 \\
\hline
\end{tabular}

Table S2: Overview of $R^{2}$ of the total dataset. Subsets of the modelled dataset were extracted and compared to the measured 10 values.

\begin{tabular}{|c|c|c|c|}
\hline & $\mathrm{R}^{2}$ total & $\begin{array}{c}\mathrm{R}^{2} \text { events only } \\
\text { (subsetted from the whole dataset) }\end{array}$ & $\begin{array}{c}\mathrm{R}^{2} \text { non-events } \\
\text { (subsetted from the whole dataset) }\end{array}$ \\
\hline$C_{D O C}$ model & 0.72 & 0.61 & 0.67 \\
\hline$S U V A_{254}$ model & 0.64 & 0.54 & 0.58 \\
\hline$S_{275-295}$ model & 0.65 & 0.79 & 0.62 \\
\hline
\end{tabular}


In the SI cited Literature

5 Lloyd, C. E. M., Freer, J. E., Johnes, P. J., and Collins, A. L.: Technical Note: Testing an improved index for analysing storm discharge-concentration hysteresis, Hydrology and Earth System Sciences, 20, 625-632, doi:10.5194/hess-20-6252016, 2016. 